\title{
X-ray Measurements of a Thermo Scientific P385 DD Neutron Generator
}

\section{CAARI}

C. J. Wharton

E. H. Seabury

D. L. Chichester

A. J. Caffrey

J. Simpson

M. Lemchak

The INL is a

U.S. Department of Energy

National Laboratory

operated by

Battelle Energy Alliance

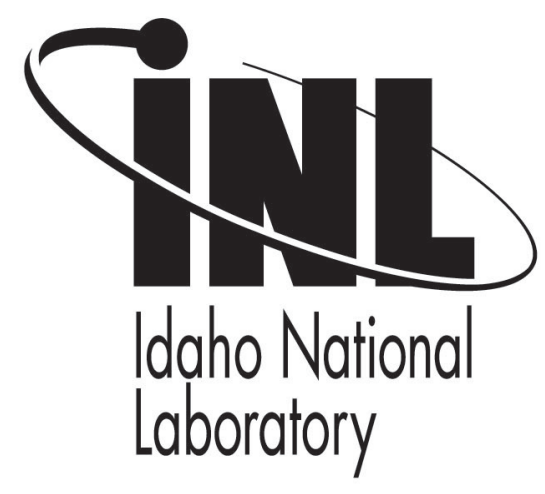

\section{August 2010}

This is a preprint of a paper intended for publication in a journal or proceedings. Since changes may be made before publication, this preprint should not be cited or reproduced without permission of the author. This document was prepared as an account of work sponsored by an agency of the United States Government. Neither the United States Government nor any agency thereof, or any of their employees, makes any warranty, expressed or implied, or assumes any legal liability or responsibility for any third party's use, or the results of such use, of any information, apparatus, product or process disclosed in this report, or represents that its use by such third party would not infringe privately owned rights. The views expressed in this paper are not necessarily those of the United States Government or the sponsoring agency. 


\title{
X-ray Measurements Of A Thermo Scientific P385 DD Neutron Generator
}

\author{
C.J. Wharton ${ }^{\mathrm{a}}$, E.H. Seabury ${ }^{\mathrm{a}}$, D.L. Chichester ${ }^{\mathrm{a}}$, A.J. Caffrey ${ }^{\mathrm{a}}$, J. Simpson ${ }^{\mathrm{b}}$, and \\ M. Lemchak ${ }^{\mathrm{b}}$
}

\author{
${ }^{a}$ Idaho National Laboratory, 2525 N. Freemont Avenue, Idaho Falls, Idaho 83415 \\ ${ }^{b}$ Thermo-Fisher Scientific/MF Physics, 5074 List Drive, Colorado Springs, Colorado 80919
}

\begin{abstract}
Idaho National Laboratory is experimenting with electrical neutron generators, as potential replacements for californium-252 radioisotopic neutron sources in its PINS prompt gamma-ray neutron activation analysis (PGNAA) system for the identification of military chemical warfare agents and explosives. In addition to neutron output, we have recently measured the x-ray output of the Thermo Scientific P385 deuterium-deuterium neutron generator. $X$ rays are a normal byproduct from neutron generators, but depending on their intensity and energy,_x rays can interfere with gamma rays from the object under test, increase gamma-spectrometer dead time, and reduce PGNAA system throughput.

The P385 x-ray energy spectrum was measured with a high-purity germanium (HPGe) detector, and a broad peak is evident at about $70 \mathrm{keV}$. To identify the source of the $\mathrm{x}$ rays within the neutron generator assembly, it was scanned by collimated scintillation detectors along its long axis. At the strongest $\mathrm{x}$-ray emission points, the generator also was rotated $60^{\circ}$ between measurements. The scans show the primary source of $\mathrm{x}$-ray emission from the P385 neutron generator is an area $60 \mathrm{~mm}$ from the neutron production target, in the vicinity of the ion source. Rotation of the neutron generator did not significantly alter the $\mathrm{x}$-ray count rate, and its $\mathrm{x}$-ray emission appears to be axially symmetric. A thin lead shield, $3.2 \mathrm{~mm}$ (1/8 inch) thick, reduced the $70-\mathrm{keV}$ generator $\mathrm{x}$ rays to negligible levels.
\end{abstract}

Keywords: PGNAA, electrical neutron generator.

PACS: $25.40 .-\mathrm{h}, 29.25 . \mathrm{Dz}$

\section{INTRODUCTION}

Idaho National Laboratory (INL) is testing the Thermo Scientific P385 deuterium-deuterium (DD) neutron generator as a potential replacement for the californium-252 neutron source in the Portable Isostopic Neutron Spectroscopy (PINS) prompt gamma-ray neutron activation analysis (PGNAA) system $^{1}$. PINS is used by military units for the nondestructive evaluation of suspect chemical warfare and explosive munitions. During normal neutron generator operation, $\mathrm{x}$ rays from the generator produced up to $90 \%$ dead time in the PINS HPGe gamma-ray spectrometer, greatly slowing data acquisition. We have carried out a set of measurements to characterize the $\mathrm{x}$-ray energy and spatial distributions, as described below.

Figure 1 shows the low energy regions of two spectra taken using a high purity germanium (HPGe) detector, one with lead wrapped around the length of the neutron generator tube, and the other without lead. A broad x-ray peak centered at $70 \mathrm{keV}$ is readily apparent in the bare-tube spectrum, and this peak was reduced greatly by the lead shielding. The neutron generator was operating at $100 \%$ duty cycle with a target current of $80 \mu \mathrm{A}$ and an accelerating voltage of $130 \mathrm{kV}$ during both measurements. 


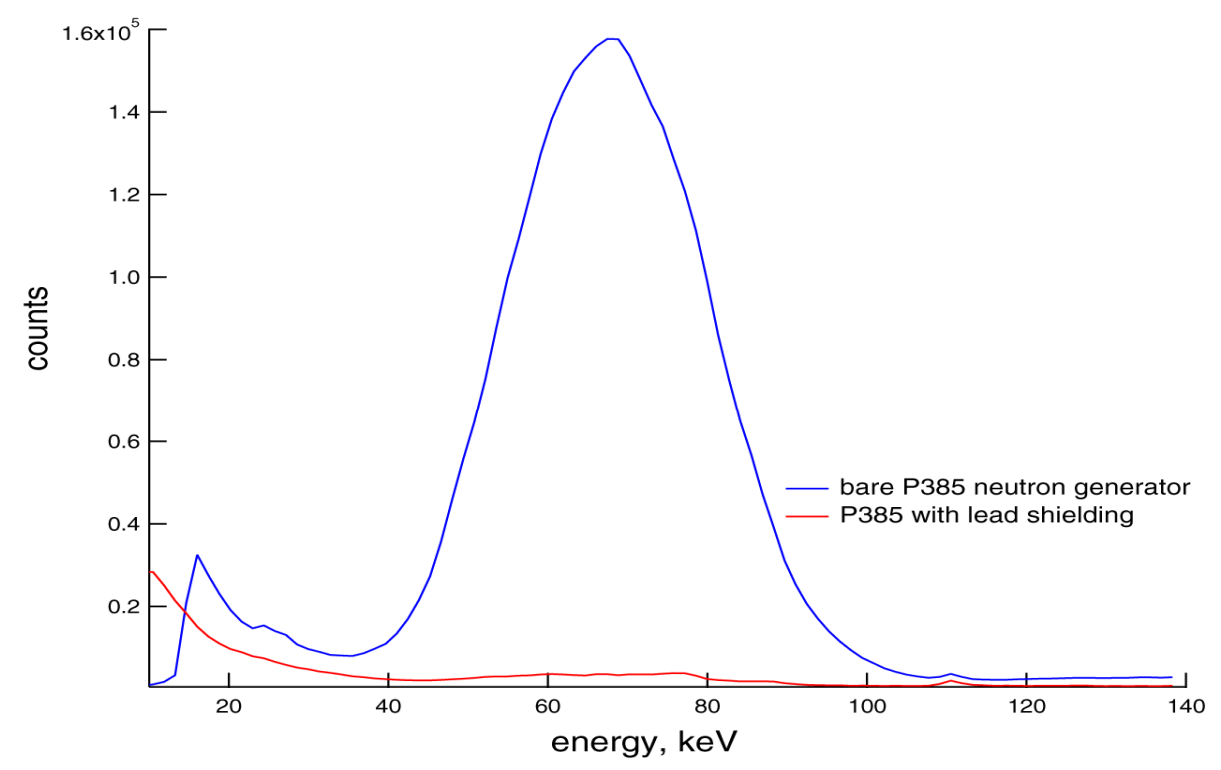

FIGURE 1. Comparison of two 100-second spectra measured with an HPGe detector using the P385 generator as the neutron source.

In order to more accurately identify the source of the $\mathrm{x}$ rays within the neutron generator tube, the lead shield was removed and the neutron generator was scanned by collimated scintillation detectors.

\section{X-RAY SCANNING METHODS}

During the scans, the neutron generator was mounted on a sliding track that was equipped with an optical linear encoder and digital readout, and the encoder precision is 0.5 microns. The generator was viewed through a $1.27-\mathrm{mm}$ by $25.4-\mathrm{mm}(0.05$-inch by 1.0 -inch) slit in a set of tungsten shielding blocks. The long axis of the slit was transverse to the long axis of the generator tube ${ }^{2}$. The generator was scanned with both a plastic scintillation detector and a sodium iodide detector, and both detector crystals were 25.4$\mathrm{mm}$ diameter by $25.4-\mathrm{mm}$ long (1.0-inch diameter by 1.0-inch long). Prior to scanning, the neutron generator target plane, marked on the outside of the generator tube with a painted line, was aligned with the viewing slit by replacing a detector with a laser pointer, and the linear encoder position was zeroed at this location.

During the scans, the neutron generator was operated at $100 \%$ duty cycle with a target current of 60 $\mu \mathrm{A}$ and an accelerating voltage of $90 \mathrm{kV}$.

\section{SCANNING RESULTS}

The scan results are presented in Figure 2, and they are discussed below.

\section{Plastic Scintillator Measurements}

An initial scan of the P385 neutron generator tube was performed using the plastic scintillation detector. The signal was passed through an amplifier, constant fraction discriminator, and scaler to determine the number of counts recorded in the detector in the energy range of the $x$ rays. Eight ten-second counting measurements were taken at various distances along a 190 millimeter length of the generator, from the end of the generator housing without cable connectors to a point approximately 60 millimeters beyond the target plane. The number of counts at each distance was recorded and averaged. For much of the scan, the distance between measurement points was 2.5 millimeters, but in areas where a large increase in counts was seen the distance between measurement points was decreased to 0.5 millimeters. The results of the scan show the primary source of $\mathrm{x}$-ray emission from the P385 neutron generator is an area $60 \mathrm{~mm}$ to the left of the neutron production target in the vicinity of the ion source.

In addition to the linear scan of the neutron generator, six measurements were performed with the detector stationary with its strongest $\mathrm{x}$-ray emission 
point at $-60 \mathrm{~mm}$ aligned with the tungsten collimator slit. The generator housing was rotated $60^{\circ}$ about its long axis between these measurements. No significant change in the count rate was observed as a function of rotation angle.

\section{NaI(TI) Detector Scan}

The plastic scintillator detector responds to both photons and fast neutrons, of course. To minimize the neutron signal, a second scan of the P385 neutron generator tube was performed using a 1-inch by 1-inch sodium iodide scintillation detector connected to an amplifier and multichannel analyzer. Data from the sodium iodide detector were collected for sixty live-seconds at each point along the neutron generator tube. Only counts with energies between 34 $\mathrm{keV}$ and $120 \mathrm{keV}$, the energy range of the $\mathrm{x}$-rays produced by the generator, were included in the sodium iodide scan tallies.
Again, the measurements were taken at various distances along a 190 millimeter length of the generator tube, from the end of the generator housing without cables to a point approximately 60 millimeters beyond the target plane. For much of this scan, the distance between measurement points was set at 5 millimeters, but in areas where a large increase in counts was determined the distance between measurement points was decreased to 0.5 millimeters.

By comparison the results of the sodium iodide detector with those of the plastic scintillator, it appears that many of the counts observed in the plastic scintillator were the results of neutron interactions, rather than $\mathrm{x}$ rays. However, both scans show interesting structure in an area $60 \mathrm{~mm}$ to the left of the neutron production target near the generator tube ion source, and we believe that most of the $\mathrm{x}$ rays are produced there.

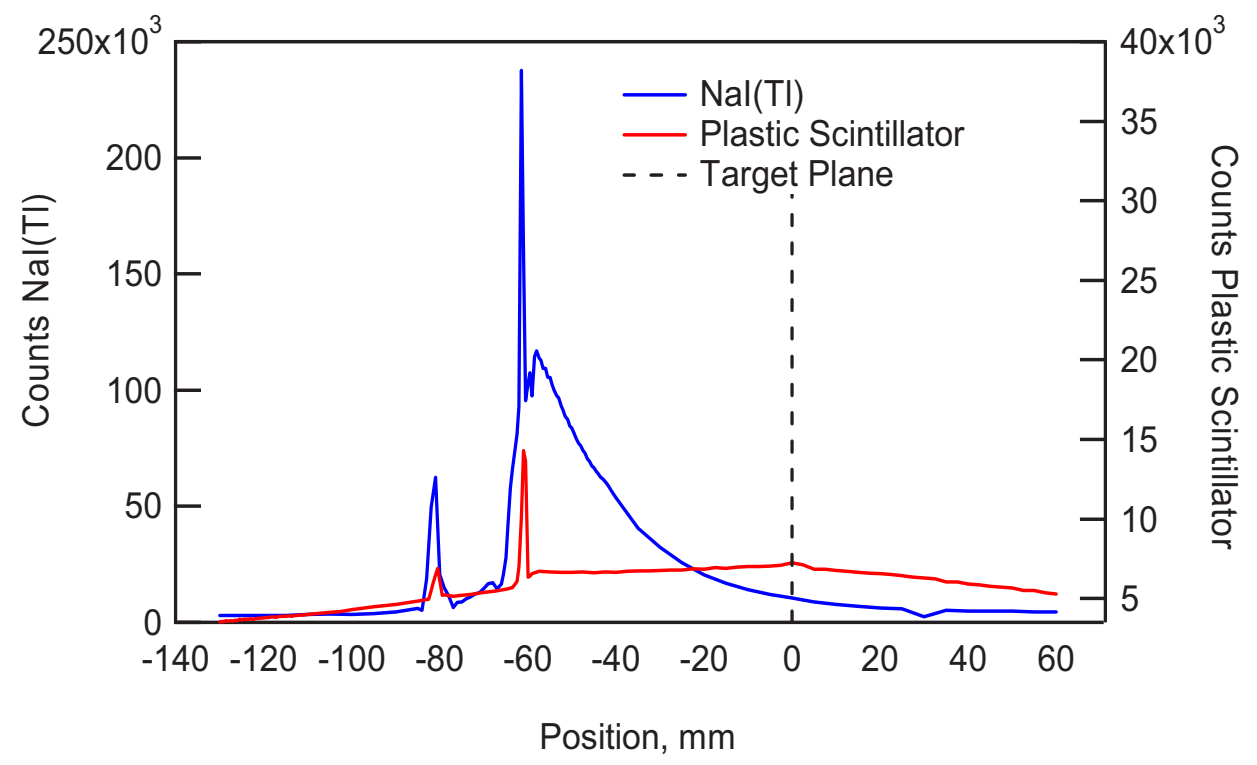

FIGURE 2. Results of scintillation detector scans along the generator's long axis.

\section{CONCLUSIONS}

The primary source of $\mathrm{x}$-ray emission from the P385 neutron generator is an area $60 \mathrm{~mm}$ to the left of the neutron production target, as viewed in Figure 2, in the vicinity of the ion source. There is a second strong emission area $80 \mathrm{~mm}$ from the target corresponding to the back of the ion tube. Rotation of the neutron generator did not significantly alter the x-ray count rate, and the x-ray emission is appears to be axially symmetric within the neutron generator.
A $3.2 \mathrm{~mm}$ (1/8-inch) thick lead shield wrapped around the generator housing reduced $\mathrm{x}$ rays counted by the HPGe detector to negligible levels, as expected from attenuation calculations, and the HPGe spectrometer fractional dead time returned to normal. Currently, we are designing a bismuth x-ray shield that will fit inside the generator housing. 


\section{ACKNOWLEDGMENTS}

This research at Idaho National Laboratory was supported by the U.S. Army Project Manager for NonStockpile Chemical Material, under U.S. Department of Energy Field Office Idaho contract DE-AC0705 ID 14517.

I would also like to thank Rahmat Aryaeinejad and Karen Wendt for their assistance.

\section{REFERENCES}

1. A.J. Caffrey et al., IEEE Trans. Nucl. Sci. 39 (1992)

1422.

2. The P385 neutron generator's housing is a stainless steel cylinder, 26 inches long and 4 inches in diameter. It has been measured to generate $\sim 5 \times 10^{6}$ neutrons per second. 